\title{
Performance and Emission Reduction using of Indian Pomegranate seed oil as bio-diesel
}

\author{
G.V.Churchill, C.Ananda Srinivasan
}

Department of Mechanical Engineering, Annamalai University, Tamil Nadu, India - 608002

\begin{abstract}
The study in made to replace the existing diesel fuel with the bio - fuels, for this fruit like Indian Pomegranate seed oil as bio - diesel is utilized. The main objective of this work is to discuss the impact of biodiesel from Pomegranate fruit seed oil bio-diesel on performance, combustion and emission characteristics diesel. In this study, the effect of bio-diesel from fruit seed oil [Indian Pomegranate seed oil] and its blends on a single cylinder Kirloskar TV-1 diesel engine were investigated.

In this work, the performance, combustion and emission analysis were conducted. The tests were performed at steady state conditions with the blend ratio of B25, B50, $B 75$ and B100. These represent the ratio of biodiesel in the blend and the rest diesel. The aim of this investigation was to reformulate the fuel to utilize the biodiesel and its blend to enhance the fuels performance, combustion characteristic and to reduce the pollution from the engine. In this work only Indian Jujube seed oil biodiesel is utilized for the experimental work. The experimental results reveal a marginal decrease in brake thermal efficiency when compared to that of sole fuel. In this investigation, the emission test were done with the help of AVL DI gas analyzer, in which CO, HC and NOx are appreciably reduced on the other hand smoke, $\mathrm{CO}_{2}$ have marginal increased when compared to that of sole fuel. In this work combustion analysis also made with the help of AVL combustion analyzer in which bio diesel blend shows the better result when compared with diesel.
\end{abstract}

Keywords-Fruit seed oil, PB - Indian Pomegranate seed oil Biodiesel, NOx - Oxides of nitrogen, Smoke.

\section{INTRODUCTION}

In the past few decades, fossil fuels, mainly petroleumbased liquid fuels, natural gas and coal have played an important role in fulfilling this energy demand. However, because of their non-renewable nature, these fossil fuels are projected to be exhausted in the near future. This situation has worsened with the rapid increase in energy demand with significant worldwide population growth. Therefore, the demand for clean, reliable, and yet economically feasible renewable energy sources has led researchers to search for new sources. Global energy demand is increasing dramatically because of rising population. According to the International Energy Agency estimation, global energy demand is expected to increase by $53 \%$ by 2030. Currently, a major part of energy demand is fulfilled by fossil fuels, globally; we consume the equivalent of more than 11 billion tons of oil in fossil fuel every year. Crude oil reserves are vanishing at a rate of 4 billion tons a year. If this rate continues, oil deposits will be exhausted by 2052. Therefore, fossil fuel stock will run out in the near future. Consequently, the world is moving toward an energy crisis; driving the world to look for alternatives many renewable energy sources have drawn the attention of researchers. Among these sources, biodiesel is the most popular choice. Biodiesel is derived from renewable resources that can be produced by a simple chemical process Many potential feed stocks are available for biodiesel production. Moreover, 60-80\% of biodiesel production cost depends on feedstock cost. The demand for both food and bio fuel has increased rapidly because of population growth. Bio diesel is useable in diesel engines in pure form (or) by blending it with petroleum diesel. Biodiesel is environment friendly and non - toxic, it emits lesser pollutants. [1].

The issue of global climate change is currently a main focus of debate and will remain as an imperative issue within the next few decades. Emissions of greenhouse gases [GHGs] from combustion of fossil fuels due to anthropogenic activity are the prime suspect for the exacerbated situation. [2]

Biodiesel has been proposed as a viable option for the supplementation of fossil fuels and is likely to be a key contributor to the global energy demand. The primary constraint for the production of biodiesel is the lack of available feedstock to produce biodiesel on a large enough scale. However, due to competition for land use space with food crops, edible oils are less of a viable option, and currently microalgae production is too expensive to be produced on a large scale, leaving nonedible oils as the best source of oils for biodiesel.[3].

Fang-xia yang et al (4) have investigated the feasibility of producing biodiesel from Idesia polycarpa var. vestita fruit oil was studied A maximum yield of over $99 \%$ of methyl esters in $I$. polycarpa fruit oil biodiesel was achieved using a 6:1 molar ratio of methanol to oil, $1.0 \%$ 
$\mathrm{KOH}\left(\%\right.$ oil) and reaction time for $40 \mathrm{~min}$ at $30{ }^{\circ} \mathrm{C}$. The fuel properties of the I. polycarpa fruit oil biodiesel obtained are similar to the No. 0 light diesel fuel and most of the parameters comply with the limits established by specifications for biodiesel. R.Sathish kumar et al (5) have studied, the optimization of transesterification process parameters for the production of Manilkara Zapota Methyl Ester (MZME) has been studied. The experimental study revealed that $50{ }^{\circ} \mathrm{C}$ temperature of reaction, $90 \mathrm{~min}$ of time of reaction, $6: 1 \mathrm{M}$ ratio of methanol to oil and $1 \mathrm{wt} \%$ of concentration of catalyst are the optimal process parameters. Also the study revealed that out of the four parameters considered, methanol to oil molar ratio is most effective in controlling the optimal biodiesel production.

Jibrail Kansedo et al (1) have studied the feasibility of converting Cerbera odollam (sea mango) oil into biodiesel. The transesterification reactions were carried out using three different catalysts; sodium hydroxide $(\mathrm{NaOH})$ as a homogenous catalyst, sulfated zirconia alumina and montmorillonite KSF as heterogeneous catalysts. The seeds were found to contain high percentage of oil up to 54\% while the yield of FAME can reach up to $83.8 \%$ using sulfated zirconia catalyst.

Mortadha A. Ali et al (7) have studied the Oil extraction from date palm seeds (Iraqi date palm) is done by standard solvent extraction method using a Soxhlet apparatus. This work is aiming to investigate the extraction of palm seed oil as a cheap feedstock for producing bio-oil and determine the fatty acid composition of bio-oil. The extraction process was carried out on a laboratory scale with particle size $2 \mathrm{~mm}, 1 \mathrm{~mm}$ and $0.425 \mathrm{~mm}$ for different time $1 \mathrm{~h}, 2 \mathrm{~h}, 4 \mathrm{~h}$ and $6 \mathrm{~h}$. Particle size of $2 \mathrm{~mm}$ was chosen in order to study the effect of solvent type. The optimal conditions to obtain the highest oil yield of $8.5 \%$ (w/w) were $120 \mathrm{~min}, 0.425 \mathrm{~mm}$ and $\mathrm{n}$ hexane extracted time, particle size of grounded seed and type of solvent, respectively.

Silitonga et al., (2) have examined the engine performance and emission characteristic of $C$. pentandra biodiesel diesel blends in internal combustion. The experimental results showed that CPB10 blend give the best results on engine performance such as engine torque and power at $1900 \mathrm{rpm}$ with full throttle condition. Besides, the brake specific fuel consumption at maximum torque (161g / $\mathrm{kWh}$ ) for CPB10 is higher about $22.98 \%$ relative to diesel fuel $(198 \mathrm{~g} / \mathrm{kW} \mathrm{h})$. This is shown that the lower biodiesel diesel blends ratio will increase the performance and reduce the fuel consumption. Moreover, the exhaust emissions showed that $\mathrm{CO}, \mathrm{HC}$ and smoke opacity were reduced for all biodiesel diesel blends.
Orkun Ozener et al., (3) have studied the combustion, performance and emission characteristics of conventional diesel fuel and biodiesel produced from soybean oil and its blends (B10, B20, B50) were compared. The experimental results, showed that, relative to diesel, biodiesel had a $1-4 \%$ decrease in the torque and an approximately 2-9\% increase in the brake-specific fuel consumption (BSFC) due to the lower heating value (LHV) of the biodiesel. However, biodiesel significantly reduced carbon monoxide (CO) (28-46\%) and unburned total hydrocarbons (THCs), while the nitric oxides ( $\mathrm{NO} x$ ) $(6.95-17.62 \%)$ and carbon dioxide $\left(\mathrm{CO}_{2}\right)$ emissions increased slightly $1.46-5.03 \%$. The combustion analyses showed that the addition of biodiesel to conventional diesel fuel decreased the ignition delay and reduced the premixed peak. These results indicated that biodiesel could be used without any engine modifications as an alternative and environmentally friendly fuel.

\section{EXPERIMENTAL PROCEDURE}

\subsection{Experimental fuels}

The commercial diesel fuel employed in the tests was obtained locally. The biodiesel produced from Pomegranate seed oil was prepared by a method of alkaline-catalyzed transesterification.

\subsection{Preparation of Biodiesel}

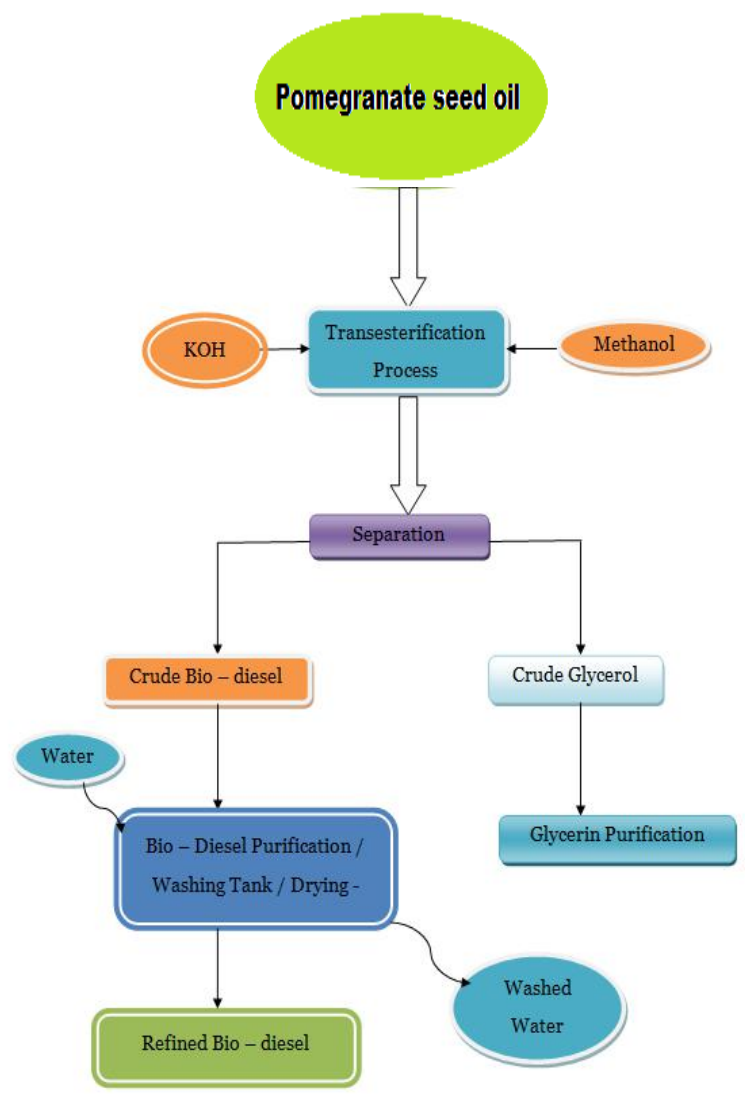

Fig.1: Indian Pomegranate Seed Oil - Bio-diesel Production Process Flow Chart. 


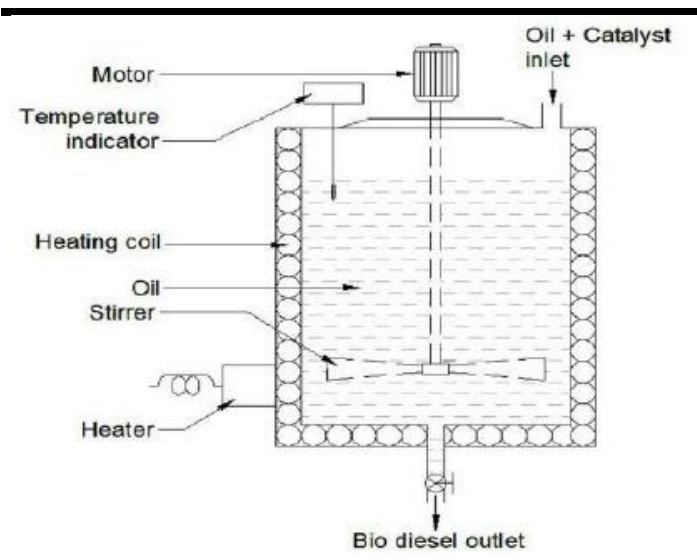

Fig.2: Schematic diagram of Biodiesel Plant

Raw Pomegranate seed oil has been purchased from local market. Biodiesel is prepared from raw oil by transesterification process. 'Alcohol mixture' is produced by mixing $200 \mathrm{ml}$ of methanol with 18 grams of Potassium Hydroxide ( $\mathrm{KOH})$. Raw Pomegranate seed oil is heated. When the temperature reaches around $60^{\circ} \mathrm{C}$ 'Alcohol mixture' is added to the raw oil. Then temperature is maintained at around $65^{\circ} \mathrm{C}$ and the mixture is stirred for about 30 minutes.

Chemical reaction took place and biodiesel got yielded. The resultant product contained biodiesel and Glycerol. The products were allowed to settle down in an inverted beaker. Separation took place and glycerol which is heavier got settled down at the bottom. Glycerol was removed and pure biodiesel was collected.

Table.1: Properties of samples

\begin{tabular}{|c|c|c|c|}
\hline $\begin{array}{c}\text { Sample } \\
\text { Name }\end{array}$ & $\begin{array}{c}\text { Specific } \\
\text { gravity }\end{array}$ & $\begin{array}{c}\text { Density } \\
\mathbf{k g} / \mathbf{m}^{\mathbf{3}}\end{array}$ & $\begin{array}{c}\text { Calorific } \\
\text { values } \\
\mathbf{k J} / \mathbf{~ k g}\end{array}$ \\
\hline Sole Fuel & 0.822 & 822 & $44,710.66$ \\
\hline Sample 1 & 0.843 & 843 & $44,193.69$ \\
\hline Sample 2 & 0.850 & 850 & $43,676.72$ \\
\hline Sample 3 & 0.851 & 851 & $43,159.75$ \\
\hline Sample 4 & 0.852 & 852 & $42,642.78$ \\
\hline
\end{tabular}

\subsection{Experimental Setup}

The investigation was carried out in Kirloskar TV I Engine. The eddy current dynamometer is coupled with the engine and is used to load the same. AVL smoke meter, AVL Di - gas analyzer and AVL combustion analyzer are connected with the engine suitably.

The engine was allowed to run using diesel at various percentages of loads $(20 \%, 40 \%$. 60\%, 80\% and maximum possible load). At each percentage of load readings related to fuel consumption, smoke density, $\mathrm{CO}$, $\mathrm{CO}_{2}, \mathrm{O}_{2}, \mathrm{HC}, \mathrm{NOx}$ and EGT were recorded. The same procedure is repeated with various blends of biodiesel (B25, B50, B75 \& B100). With each blend the engine is run at various percentages of loads $(20 \%, 40 \%, 60 \%, 80 \%$ and maximum possible load). At each load readings corresponding to performance, emission and combustion characteristics are recorded. The results of these experiments are analyzed and discussed.

Table.2: Specification of the test engine

\begin{tabular}{|c|c|}
\hline Type & $\begin{array}{c}\text { Vertical, Water cooled, } \\
\text { Four stroke }\end{array}$ \\
\hline Number of cylinder & One \\
\hline Bore & $87.5 \mathrm{~mm}$ \\
\hline Stroke & $110 \mathrm{~mm}$ \\
\hline Compression ratio & $17.5: 1$ \\
\hline Maximum power & $5.2 \mathrm{~kW}$ \\
\hline Speed & $1500 \mathrm{rev} / \mathrm{min}$ \\
\hline Dynamometer & Eddy current \\
\hline Injection timing & $23^{\circ} \mathrm{before} \mathrm{TDC}$ \\
\hline Injection pressure & $220 \mathrm{~kg} / \mathrm{cm}^{2}$ \\
\hline
\end{tabular}

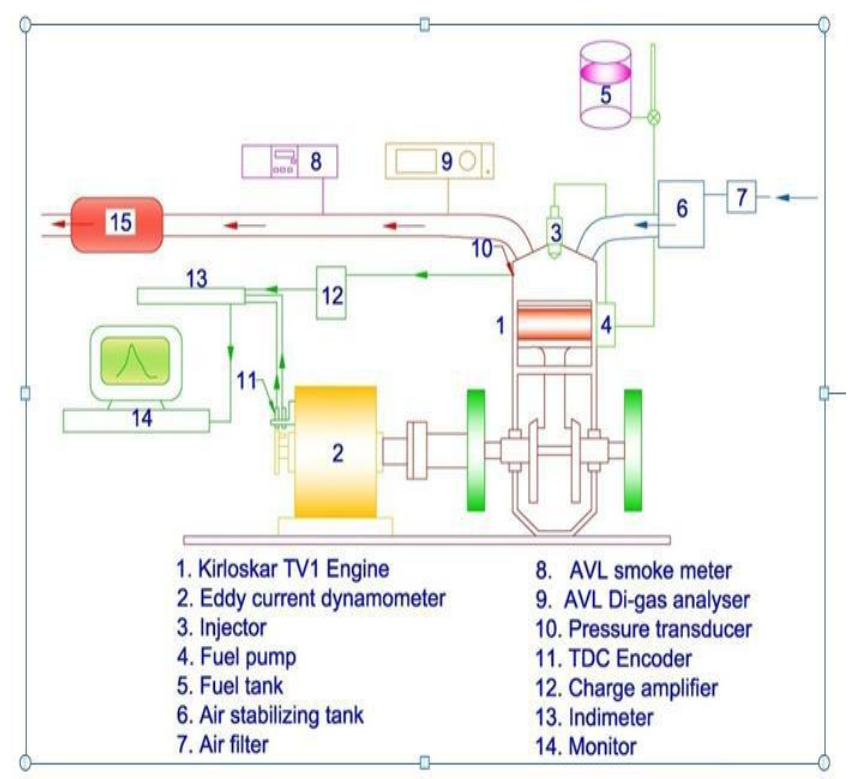

Fig.3: Experimental setup

\section{RESULTS AND DISCUSSION}

Engine performance with biodiesel or its blends with diesel fuel depends largely on the combustion, air turbulence, air-fuel mixture quality, injector pressure, actual start of combustion and many other singularities that make test results vary from one engine to another. In addition, it can vary depending on the quality and origin of biodiesel as well as engine operating parameters like speed, load, etc. Generally, the blend of non-edible biodiesel with mineral diesel can be applied directly to CI diesel engines. However, the effect of using this biodiesel 
must be evaluated by determining engine power/torque, brake thermal efficiency, brake specific fuel consumption and emissions production. Extensive research has been conducted worldwide to utilized non-edible biodiesel as a possible fuel for use in a diesel engine. Series of experiments by using blended non-edible bio- diesel for compression ignition engines have focused on engine performances and emissions. This section reviews the effects of blending non-edible biodiesel on engine performance, emission and combustion characteristics in DI diesel engine.

The experiment is performed for Pomegranate seed oil biodiesel. The results of the experimental investigations carried out have been furnished hereunder for Jujube seed oil biodiesel.

\subsection{Brake Thermal Efficiency}

The effect of Biodiesel blend on brake thermal efficiency is shown in figure 1. It can be seen from the figure 3.1 that Brake thermal efficiency in general reduced with the increasing proportion of biodiesel in the test fuels. The brake thermal efficiency for B25, B50, B75 and B100 was less than that of sole fuel by about approximately $14 \%$ for B25, B50, B75 and $17.5 \%$ for B100 in the maximum load of $5.2 \mathrm{~kW}$. This is due to the effect of biodiesel blend. This may also be due to the higher viscosity, density and lower heating value than the sole fuel. The higher viscosity leads to decreased atomization, fuel vaporization and combustion and hence the thermal efficiency of biodiesel is lower than that of the sole fuel. Fuel consumption increases due to higher density and low heating value consequently, thermal efficiency decreases. Whereas the thermal efficiency is higher in case of blend fuels as compared to pure biodiesel (B100).

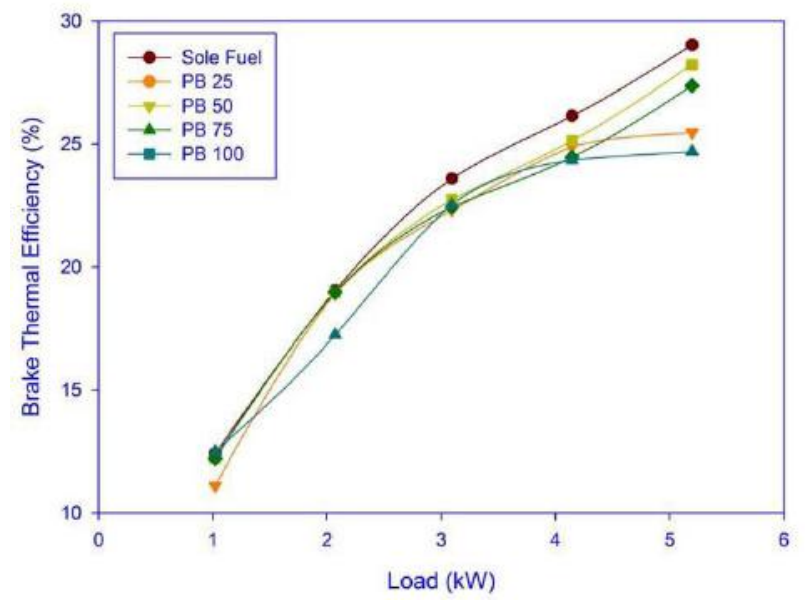

Fig .3.1 Brake Thermal Efficiency against Load

\subsection{Exhaust Gas Temperature}

The effect of biodiesel blend on exhaust gas temperature is show figure 3.2. It can be seen from the figure 3.2 that the exhaust gas temperature is reduced for the entire biodiesel blend with the increasing proportion of biodiesel in the test fuels. Due to the effect of biodiesel blend the minimum exhaust gas temperature is $180^{\circ} \mathrm{c}$ at $20 \%$ load for B75 which is minimum when compared to that of other samples.

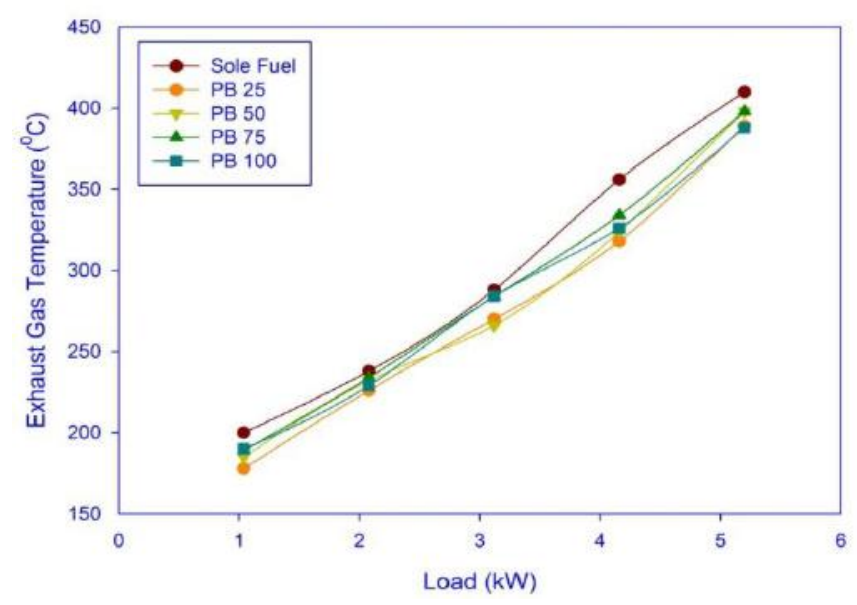

Fig.3.2: Exhaust Gas Temperature against Load

The reduction in temperature may be due to faster combustion rates of biodiesel blend. Due to the improvement in the diffusion combustion rate, late burning of biodiesel is reduced and thus results in a reduced exhaust gas temperature. Also biodesel has high latent heat of vaporization property which cools the charges and thus reduced the peak combustion temperature. Hence lower exhaust gas temperature. Also, the presence of oxygen in the biodiesel decreases the heating value of biodiesel by $10 \%$ to $13 \%$ compared to the heating value of diesel fuel.

\section{EMISSION CHARACTERISTICS}

\subsection{CO emission}

The effect of the biodiesel blend on the $\mathrm{CO}$ emission is shown in figure 3.3 for the biodiesel and its blends, the $\mathrm{CO}$ emissions where less than that of sole fuel. The least $\mathrm{CO}$ emissions have been obtained for the B25 with the value of $0.05 \%$ by volume at $40 \%$ load to be found approximately $12 \%$ for B25 and B50, 6\% for B75 and 2\% for $\mathrm{B} 100$ reductions in $\mathrm{CO}$ emissions. The reduction of $\mathrm{CO}$ is due to the oxygen content on the biodiesel. 


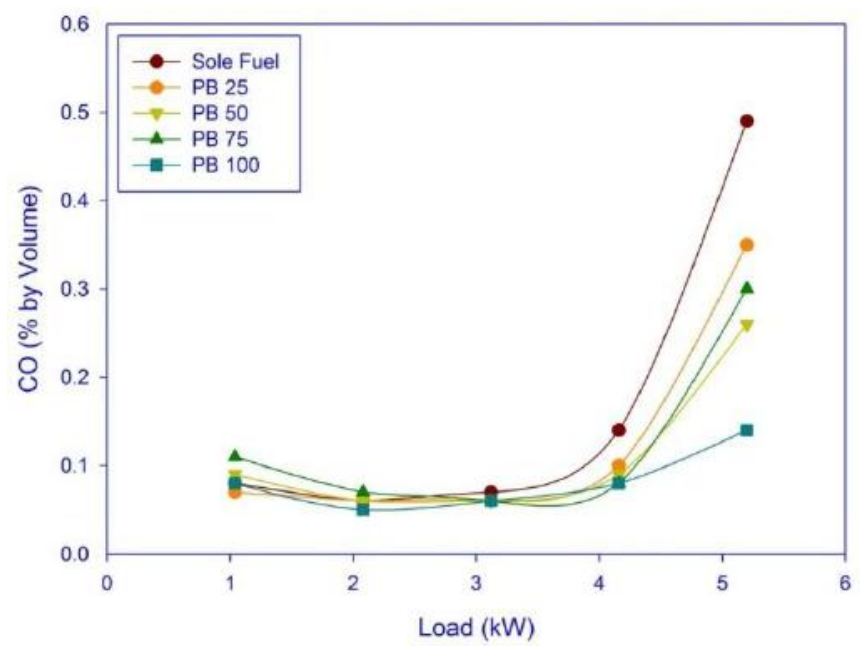

Fig. 3.3: CO against brake power

In comparison with sole fuel, $\mathrm{CO}$ emissions showed a trend of decreasing with the increase in biodiesel blend ratios. CO emission decreased due to fuel properties of biodiesel such as higher oxygen content, which promote the complete combustion. The variation of $\mathrm{CO}$ emission at different loads is shown in Fig. At low and medium loads, CO emissions of the blends were not much different from those of sole fuel. However, at full load, $\mathrm{CO}$ emissions of the blends decreased significantly when compared with those of standard diesel. This can be explained by the enrichment of oxygen owing to the biodiesel addition, in which an increase in the proportion of oxygen promotes further oxidation of $\mathrm{CO}$ during the engine exhaust process. There was a $30 \%$ reduction of $\mathrm{CO}$ emission for the B25 and B50 blend.

\section{4 $\mathrm{CO}_{2}$ emission}

The effect of the biodiesel blend on the $\mathrm{CO}_{2}$ emission is shown in figure 7.4 for the biodiesel and its blend, the $\mathrm{CO}_{2}$ emission is where less up to $40 \%$ load after that the $\mathrm{CO}_{2}$ emission is increased for all the biodiesel blends. The $\mathrm{CO}_{2}$ emission is maximum for $\mathrm{B} 100$ at maximum load with a value of $7.1 \%$ by volume. This is because of availability of excess oxygen for complete combustion of fuel and also the effect of the increasing in the Bio-diesel $\%$ it is observed that Emission increases gradually as the load increases for all the blended fuels. This is due to the effect of lower operating temperature with high latent heat of vaporization.

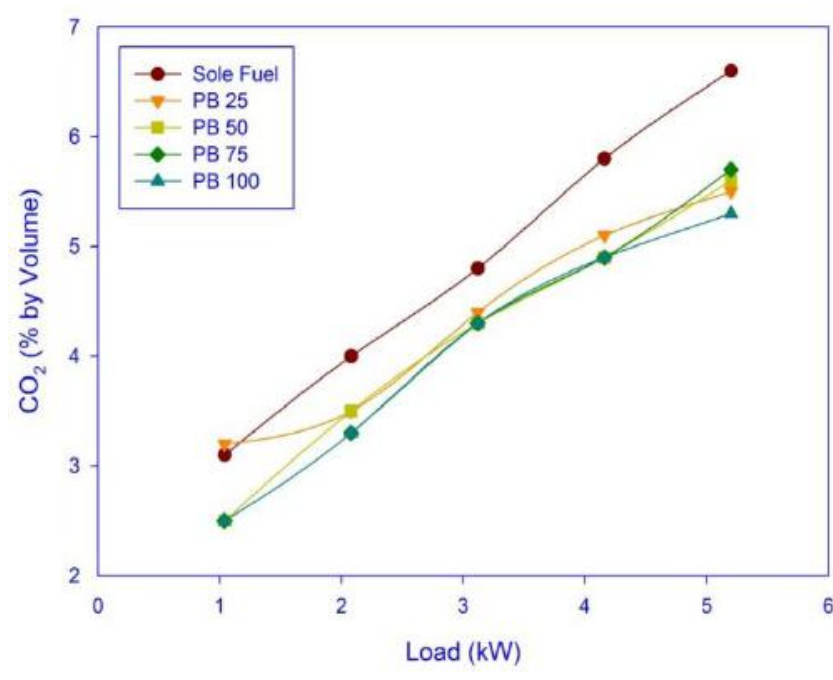

Fig.3.4: $\mathrm{CO}_{2}$ against Load

\subsection{HC Emissions}

The effect of Biodiesel on hydrocarbon emission is shown in figure 3.5. It is observed that the $\mathrm{HC}$ emission is minimum for B100 with a value of $34 \mathrm{ppm}$ at maximum load. The HC emission is lower when compared to that of the sole fuel for all the samples. There is marginal decrease of $\mathrm{HC}$ emission for all the samples. But for the $\mathrm{B} 100 \mathrm{HC}$ emission is decreased effectively when compared to other samples. The HC emission increases up to $60 \%$ and decrease after that. This may be due to the presences of higher amount of oxygen content in Biodiesel with high latent heat of vaporization. For $100 \%$ Bio-diesel the HC emission level is less when compared to the sole fuel.

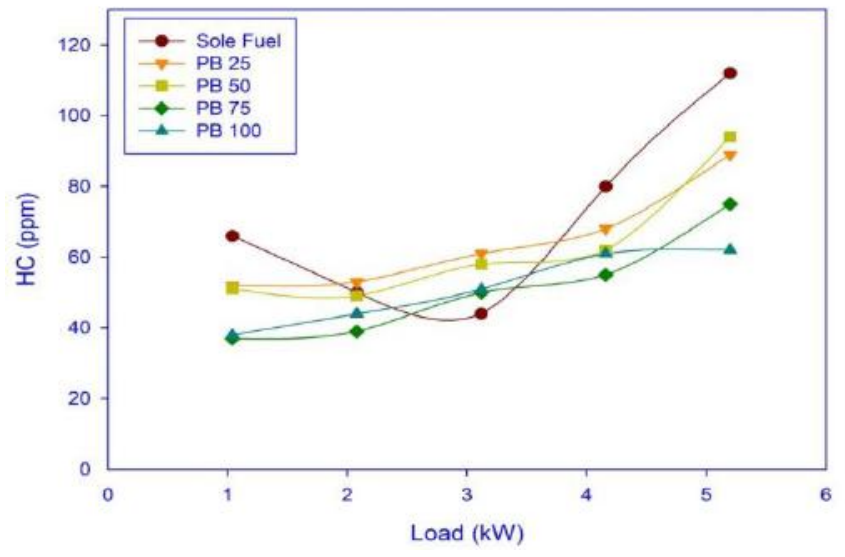

Fig.3.5: HC Emission against Load

\subsection{NOx Emission}

The effect of biodiesel on NOx emission is shown in figure 3.6. for the biodiesel and its blend the NOx emission where less than that of sole fuel. The NOx emission is minimum for B100 with a value of $960 \mathrm{ppm}$ 
at $100 \%$ Similarly for B100 at maximum load is $10.2 \mathrm{ppm}$ which is less when compared to all other samples at maximum load. This is due to the effect of oxygen content in the biodiesel. This is also due to high latent heat of vaporization and lower calorific value of the Biodiesel blends, which reduces the in-cylinder temperature and thus reduces the $\mathrm{No}_{x}$ emission.

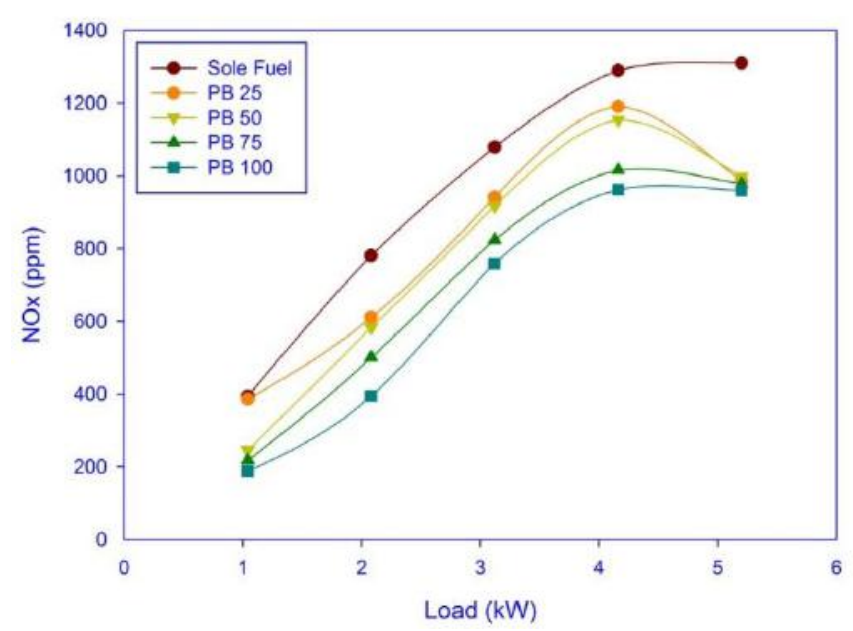

Fig.3.6: No Emission against Load

\subsection{Smoke Density}

The effect of biodiesel on smoke emission is shown in figure 3.7 for the biodiesel and its blends the smoke emission is higher when compared to the sole fuel. It is observed for all the samples the smoke emission is higher than that of sole fuel. The maximum smoke value is $74.06 \mathrm{HSU}$ for B100 at maximum load.

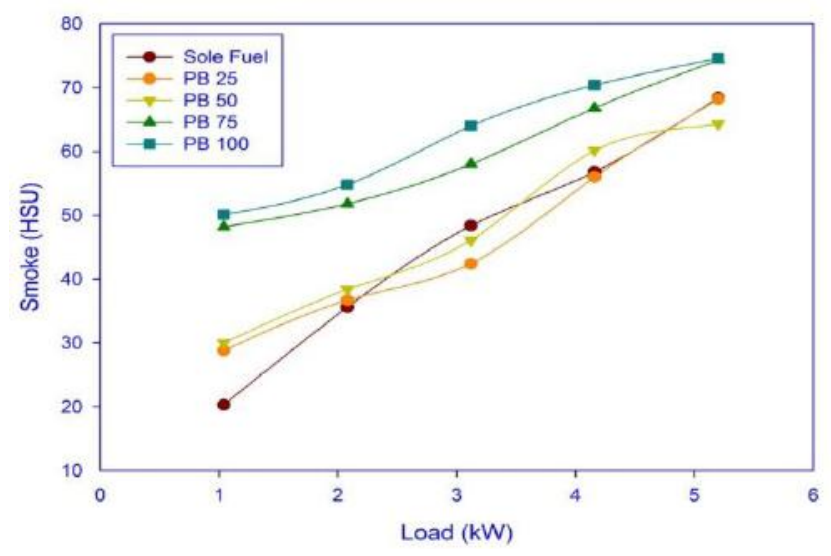

Fig.3.7: Smoke Density against Load

\section{a. Cylinder Pressure}

\section{COMBUSTION PARAMETERS}

Fig 4.1 shows cylinder pressure for various values of crank angle. The peak pressure within the cylinder is 72.129 bar . The maximum peak pressure for B100. It is clear that the peak cylinder pressure is increased with the increase of engine load. The peak cylinder pressure does not vary significantly with the increase of engine speed.
The combustion process of the test fuels is similar, consisting of a phase of premixed combustion following by a phase of diffusion combustion. At low engine load, only a small amount of fuel is burned and the fuel is burned mainly in the premixed burning phase. As the engine load decreases, the residual gas temperature and wall temperature decrease which leads to lower charge temperature at injection timing, and lengthens the ignition delay. Ignition delay represents the time taken in physical and chemical reactions and does not change much on a time scale of milliseconds. However, it will increase in terms of crank angle degrees with engine speed increase as a high engine speed will correspond to a larger crank angle for the same time duration. Fig 4.1 show the pressure rise rate of the tested fuels at different engine operating conditions. It is clear that the peak of pressure rise rate increases with the increase of engine load, and does not vary significantly with the increase of engine speed.

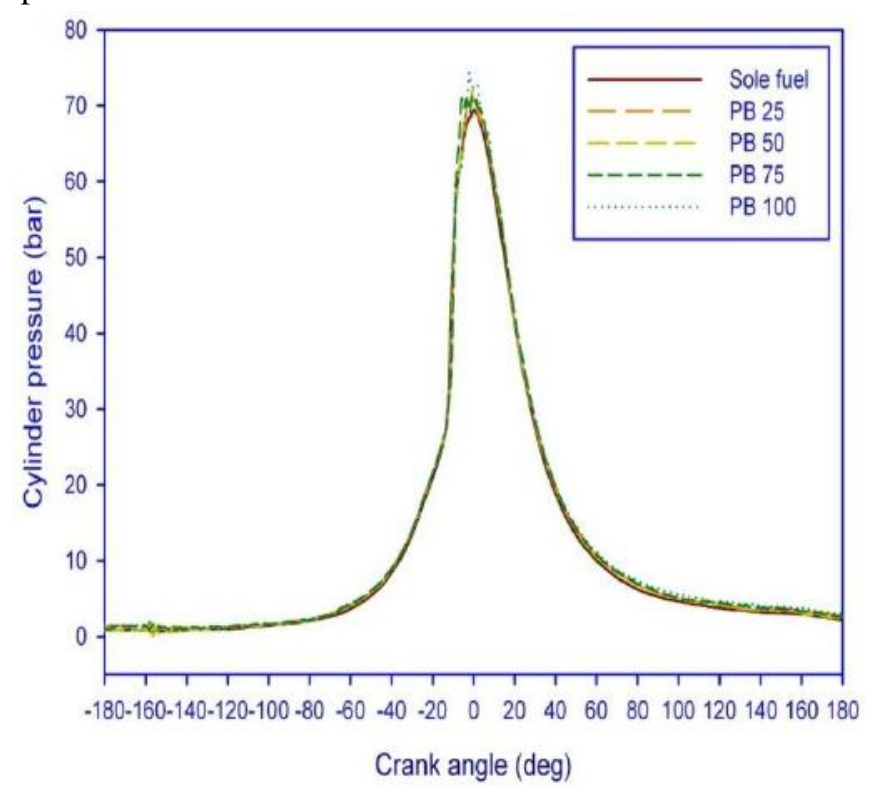

Fig.4.1: Cylinder Pressure against Crank angle

\section{b. Heat Release Rate}

Fig 4.2. Shows heat release rate for various values of crank angle. The heat release rate of conventional combustion chamber is higher than that sole fuel. The maximum heat release rate is $150.783 \mathrm{~kJ} / \mathrm{m}^{3} \mathrm{deg}$ for $\mathrm{B} 75$. The variation of heat release rate at different engine operating conditions is shown in Fig 4.2. Because of the evaporation of the fuel accumulated during ignition delay period, at the beginning a negative heat release rate is observed. After combustion is initiated, this becomes positive. After the ignition delay, premixed fuel-air mixture burns rapidly, follow by diffusion combustion, where the burn rate is controlled by fuel-air mixing velocity. At high engine load, the peak of heat release rates of $\mathrm{B} 75$ are evidently higher than that of other and 
the crank angle of the peak of heat release rate is almost the same. The reason may be that the premixed burning heat release is higher for $\mathrm{B} 75$.

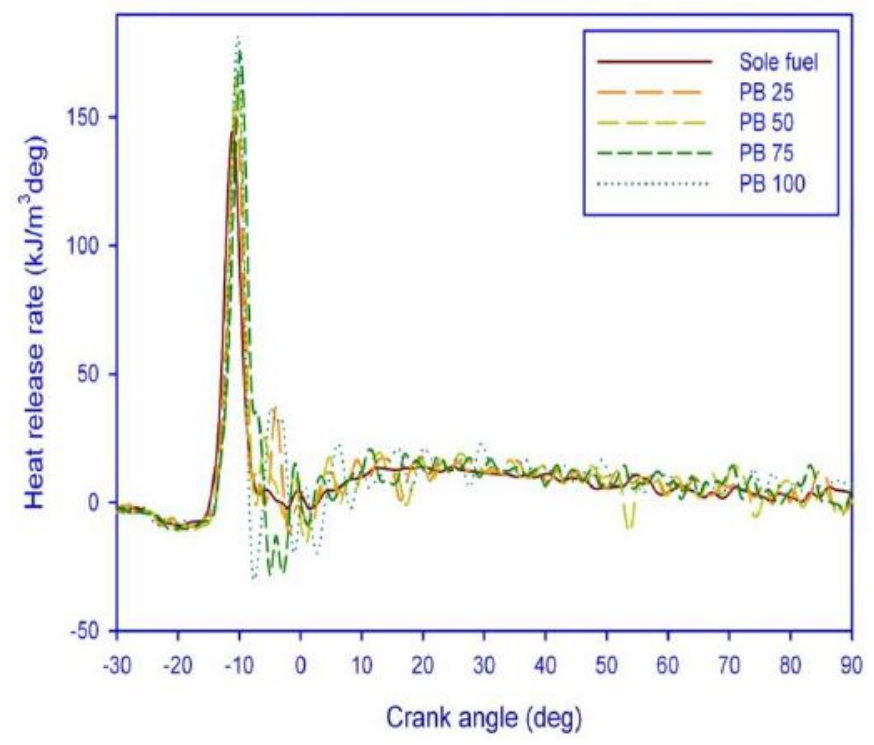

Fig.4.2: Heat release rate against Crank angle

\section{CONCLUSION}

Bio-diesel has attracted much research because of its economic and environmental benefits as well as its renewable origin. Bio-diesel produced from non-edible oil resources can defy the use of edible oil for Bio-diesel production. Therefore, its demand is growing steadily, and researchers are lucking for possible newer sources of non-edible oil. This review concludes that non-edible oil is a promising source that can sustain Bio-diesel growth.

\section{From the study this is deduced that}

1. The brake thermal efficiency is marginally decreased for the biodiesel and its blend.

2. The exhaust gas temperature is lower for PB25 is 180

3. The emission analysis for the biodiesel and its blend gave the best result when compared to the sole fuel.

- The CO emission is reduced by $0.14 \%$ by volume at $100 \%$ of load for PB 100 .

- The $\mathrm{CO}_{2}$ emission is decreased by $5.3 \%$ by volume at $100 \%$ of load for PB 100 .

- The $\mathrm{HC}$ emission is reduced by $62 \mathrm{ppm}$ at $100 \%$ of load for PB100.

- $\quad$ The $\mathrm{NO}_{\mathrm{x}}$ emission is reduced by $960 \mathrm{ppm}$ at $100 \%$ of load for PB 100 .

- Smoke density is increased by $74.06 \mathrm{HSU}$ at $100 \%$ of load for PB 100 .

4. The combustion parameters for the biodiesel and its blends gave the best result.

- The maximum cylinder pressure is 72.129 bar for PB100.
- The maximum heat release rate is 150.783 $\mathrm{kJ} / \mathrm{m}^{3} \mathrm{deg}$ for PB 100 .

- $\quad$ The peak cylinder pressure is 74.912 bar for B75 at $41^{\text {st }}$ cycles.

\section{REFERENCES}

[1] A.M. Ashraful, H.H.Masjuki, M.A. Kalam, I.M. Rizwanul Fattah, S.A. Shahir, H.M. Mobarak, “ Production and comparison of fuel properties, engine performance, and emission characteristic of biodiesel from various non-edible vegetable oils”,Energy Conversion and Management 80 (2014) PP202- 228

[2] Steven Lim, Keat Teong Lee "Process intensification biodiesel production from jatropha curcas L.seeds: Supercritical reactive extraction process parameters study" Applied Energy 103 (2013) pp712 - 720

[3] Yixin Zhu ${ }^{\text {a,b }}$, Jianchu $\mathrm{Xu}{ }^{\mathrm{a}, \mathrm{b}}$, Qiaohong $\mathrm{Li}^{\mathrm{a}}{ }^{\mathrm{a}, \mathrm{b}}$, Peter E.Mortimer a,b "Investigation of rubber seed yield in Xishuangbanna and estimation of rubber seed oil based biodiesel potential in southeast Asia" Energy 69 (2014) pp $837-842$

[4] Fang-Xia Yang ${ }^{a}$, Yin-Quan su ${ }^{a}$, Xiu-Hong $\mathrm{Li}^{\mathrm{a}}$, Qiang Zhanga, Run-Cang Sun ${ }^{\mathrm{b}, \mathrm{c}^{*}}$ "Preparation of biodiesel from Idesia Polycarpavar. Vestita fruit oil" Industrial Crops and Products 29 (2009) pp622 628

[5] R.Sathish Kumara, K.Sureshkumara, R.Velraj ${ }^{\mathrm{b}}$ "optimization of biodiesel production from Manilara Zapota (L.) Seed oil using Taguchi method" Fuel 140(2015) PP90 -96

[6] Jibrail Kansedo, Keat Teong Lee*, Subhash Bhatia "Cerbera odollam (sea mango) oil as a promising non-edible feedstock for biodiesel production." Fuel 88(2009) pp1148 - 1150.

[7] Mortadha A. Ali ${ }^{1, *}$ Tahseen A. Al-Hattab ${ }^{1}$, Imad A. Al-Hydary " "Extraction of Date Palm seed oil (Phoenix Dactylifera) By Soxhlet Apparatus." International Journal of Advances in Engineering \& Technology, June 2015 ISSN 223311963

[8] Ogunsuyi H.O, "Acid and Base Catalysed Transestrification of Mango (Mangifera Indica) Seed Oil to Biodiesel" IOSR Journal of Applied Chemistry (IOSR-JAC) Volume 2, Issue 2 (Sep-Oct. 2012), PP 18-22.

[9] Yathish. K.V, "Biodiesel Production From Custard Apple Seed (Annona Squamosa) Oil And Its Characteristics Study" International Journal of Engineering Research \& Technology (IJERT) Vol. 2 Issue 5( May - 2013).

[10]Nakorn Tippayawong and Phichet Chumjai, "Characterization and Performance of Biofuel from 
Passion Fruit Processing Residues" Proceedings of the World Congress on Engineering and Computer Science 2012 Vol II WCECS 2012, October 24-26, 2012, San Francisco, USA.

[11] Singh.R.N, "SPRERI experience on holistic approach to utilize all parts of Jatropha curcas fruit for energy" Thermochemical Conversion Division, Sardar Patel Renewable Energy Research Institute, Vallabh Vidyanagar 388 120, Gujarat, IndiaReceived 1 February 2007; accepted 21 October 2007 Available online 20 February 2008, PP 1868-1873.

[12] Silitonga.A.S ,"Experimental study on performance and exhaust emissions of a diesel engine fuelled with Ceiba pentandra biodiesel blends" Volume 76, December 2013, PP 828-836.

[13] Orkun Ozener, "Effects of soybean biodiesel on a DI diesel engine performance, emission and combustion characteristics" Volume 115, January 2014, PP 875883. 